\title{
Aplikasi Keamanan Pangan dan Teknologi Pengemasan Produk Jamu Alona Guna Peningkatkan Kinerja Produk
}

\author{
Ike Sitoresmi, Sujiman, Ali Maksum \\ Jurusan Teknologi Pertanian Fakultas Pertanian \\ Universitas Jenderal Soedirman, \\ E-mail : ikesitoresmi@yahoo.co.id \\ DOI: http://dx.doi.org/10.21107/pgd.v5i1.5160
}

\begin{abstract}
Artikel Diterima : 5 Desember 2018/ Revisi : 10 Februari 2019/Terbit : 15 April 2019
Abstrak

Minuman fungsional alami asli dari Indonesia adalah Jamu. Usaha rumah tangga jamu Alona memproduksi jamu kunir Asam dan Kunir Asam Sari Rapet. Namun produk yang dihasilkan memiliki masa simpan yang pendek. Untuk itu perlu dilakukan alih teknologi pengolahan dan pengemasan yang tepat agar masa simpan produk lebih lama. Metode yang digunakan dalam pengabdian ini adalah penyuluhan dan pendampingan dengan materi pendampingan: teknologi pengolahan, teknologi pengemasan dan nerasa keuangan. Hasil penemuan kondisi di lapangan menunjukan bahwa dari sisi pengolahan perlu dilakukannya blanching bahan baku selama 15 menit dan perebusan ekstraksi kunyit selama 15 menit. Melakukan pengemasan pada kondisi yang aseptis dan pencelupan produk akhir pada air mendidih selama 5 menit. Kedua hal tersebut mampu meningkatkan umur simpan produk dari 5 hari menjadi 7 hari pada suhu $4^{\circ} \mathrm{C}$. Omset produksi mengalami kenaikan sebanyak $20 \%$.
\end{abstract}

Kata Kunci : jamu, kunir, penyuluhan, pengolahan, pengemasan

\section{PENDAHULUAN}

Jamu tradisional, adalah minuman berbahan rempah rempah alami Indonesia yang dipercaya memiliki khasiat kesehatan bagi tubuh bila mengkonsumsinya. Maraknya gerakan untuk mengkonsumsi segala sesuatu yang berbau alami dan kondisi jaman sekarang yang menuntut segala sesuatu yang serba praktis, berakibat pada semakin prospektifnya usaha pembuatan jamu siap saji.

Peluang ini disadari oleh Ibu Yogi Rahayu, pemilik usaha Jamu "ALoNa" yang memproduksi jamu gendong terutama jamu Kunir Asem danJamu Kunir Asem Sari Rapet. Jamu AloNa berdiri sejak 23 Juni 2014. Usaha pembuatan Jamu Tradisional yang berlokasi di Perumahan Kedungwringin Blok $F$ no 8 Kecamatan Patikraja masih melakukan proses produksi dengan cara manual dan tradisional. Jamu AloNa menggunakan bahan bahan yang masih segar, tanpa pemanis buatan dan pengawet menjadikan jamu produksi Alona ini sangat dipercaya oleh konsumennya. Hal ini terbukti dari terjaganya kesetiaan konsumen dalam mengkonsumsi jamu selama 3 tahun lebih produk jamu AloNa ini. Namun ternyata produk jamu Alona ini memiliki umur simpan yang relatif pendek yaitu hanya 2 hari di suhu ruang dan 4 hari pada suhu refrigerator. Hal ini mengakibatkan pasar produk Alona hanya sekitar Purwokerto dan produksi lebih didasarkan pada pemesanan. Sehingga meski dimulai sejak 3 tahun lalu, omset yang dicapai oleh usaha jamu ini masih tergolong sedikit yaitu Rp 5.000.000,per bulan.

Bahan dasar jamu kunyit asam dan kunyit asam sirih adalah rimpang kunyit. Nilai jual rimpang kunyit tanpa olah di tingkat petani sangat rendah. Harga rimpang kunyit yang wajar di tingkat petani adalah $\mathrm{Rp} 1.000,-/ \mathrm{kg}$ (Lestari, 2015). Selain nilai jual yang rendah, pangsa pasar penjualan komoditas tersebut sangat terbatas, sehingga kurang menarik minat petani untuk meningkatkan produksi komoditas tersebut secara intensif. Peningkatan produksi komoditas dilakukan dengan pengoptimalan industri pengembangan produk melalui diversifikasi produk. Peningkatan nilai tambah melalui diversifikasi produk dapat memperluas pangsa pasar rimpang kunyit, sehingga dapat meningkatkan pendapatanpetani (Permana, 2008).

Kunyit adalah kelompok tanaman rimpangrimpangan (Zingiberaceae) yang sering digunakan sebagai bahan baku dalam produk minuman fungsional. Kunyit (Curcuma domestica), dengan kandungan bioaktif yaitu kurkumin dan minyak atsiri, dapat diolah sebagai 
bahan baku minuman fungsional, yaitu minuman kunyit asam karena di dalamnya banyak mengandung senyawa antibakteri, antiinflamasi, dan antioksidan (Chan, et al., 2008). Produk minuman berbahan baku biofarmaka memiliki beberapa keunggulan diantaranya memiliki aspek fungsional bagi kesehatan, praktis dalam penggunaan, dan kemudahan transportasi. Namun, kandungan senyawa bioaktif yang terdapat dalam produk minuman kunyit mudah mengalami kerusakan pada saat penyimpanan pada suhu kamar. Kerusakan tersebut dapat diperlambat dengan menggunakan metode yang tepat, misalnya dengan menggunakan metode pengemasan..

Menurut Suyitno (1990), pengemasan merupakan salah satu bagian dari pengolahan pangan. Pengemasan mempunyai dua fungsi utama, yaitu keperluan periklanan dan untuk melindungi makanan. Jenis kemasan terutama kemasan primer berpengaruh secara spesifik terhadap produk yang dikemas. Beberapa jenis kemasan yang dapat digunakan untuk produk minuman tradisional jamu adalah botol plasik polipropilen, botol kaca bening dan botol kaca gelap..

Daya simpan produk yang dikemas sangat dipengaruhi oleh nilai permeabilitas kemasan. Hal tersebut dikarenakan nilai permeabilitas akan mempengaruhi perubahan kadar air. Menurut Gunasoraya (2011), permeabilitas uap air kemasan adalah kemampuan uap air untuk menembus suatu kemasan pada kondisi suhu dan RH tertentu, sehingga semakin kecil permeabilitas air kemasan maka daya tembus uap air semakin kecil, begitupun sebaliknya.
Oleh karena itu kegiatan Pengabdian Kepada Masyarakat Penerapan Ipteks ini ingin menggandeng mitra Usaha Jamu Tradisional AloNa untuk memberikan contoh teknologi pengolahan jamu yang tepat serta aplikasi teknologi pengemasan dan penyimpanan yang sesuai. Aplikasi yang tepat diharapkan mampu memperpanjang umur simpan meningkatkan value produk sehingga meningkatkan omset produk.

\section{METODE}

Metode yang dilaksanakan dalam kegiatan Pengabdian kepada Masyarakat program Penerapan Iptek ini adalah kegiatan penyuluhan dan pendampingan yang melibatkan mitra usaha jamu tradisional AloNa di Desa Kedungwringin Kecamatan Patikraja sebagai kelompok sasaran Pelaksanaan alih teknologi antara Tim Pengabdian bekerja sama dengan Tim penggerak PKK desa Kedungwringin dengan usaha jamu tradisional AloNa berupa teknologi proses pengolahan produk dan teknologi pengemasan dengan labeling terstandar dilakukan dengan metode belajar aktif. Melalui metode ini, mitra diberikan pemahaman terlebih dahulu kemudian dilakukan pendampingan secara aktif.

Pendampingan dilakukan dengan sasaran pengaplikasian teknologi yang disampaikan sebelumnya pada lini produksi ukm sasaran. Pendampingan diperlukan aagar pelaksanaan dilakukan sebagaimana mestinya dan agar segera dapat diketahui permasalahan yang timbul dan dijumpai di lapangan. Dalam proses ini ukm dapat berperan aktif mulai dari perencanaan penentuan desain kemasan, penerapan pada

Tabel 1. Materi Pelaksanaan Kegiatan Pengabdian

\begin{tabular}{|c|c|c|c|}
\hline $\begin{array}{c}\text { No } \\
\text { Pertemuan }\end{array}$ & $\begin{array}{c}\text { Materi yang } \\
\text { disarankan untuk dibahas }\end{array}$ & Khalayak sasaran & $\begin{array}{c}\text { Tempat } \\
\text { Pertemuan yang } \\
\text { disarankan } \\
\end{array}$ \\
\hline $\mathrm{I}$ & $\begin{array}{l}\text { Teknologi proses } \\
\text { pengolahan jamu tradisional } \\
\text { 1. Titik Kritis proses } \\
\text { pengolahan } \\
\text { 2. Sanitasi }\end{array}$ & Mendengarkan \& Diskusi & $\begin{array}{l}\text { Sanggar PKK / tempat yang } \\
\text { disepakati anggota }\end{array}$ \\
\hline II & Pendampingan & $\begin{array}{l}\text { Partisipasi aktif dalam } \\
\text { kegiatan produksi }\end{array}$ & Lokasi UKM \\
\hline III & $\begin{array}{l}\text { Teknologi pengemasan } \\
\text { 1. Desain kemasan } \\
\text { 2. Labeling terstandar }\end{array}$ & Mendengarkan \& Diskusi & $\begin{array}{l}\text { Sanggar PKK / tempat yang } \\
\text { disepakati anggota }\end{array}$ \\
\hline IV & Pendampingan & $\begin{array}{l}\text { Partisipasi aktif dalam } \\
\text { kegiatan produksi }\end{array}$ & Lokasi UKM \\
\hline $\mathrm{V}$ & Neraca Usaha & Diskusi dan Partisipasi aktif & Lokasi UKM \\
\hline
\end{tabular}


produk dan evaluasi alternatif yang ada sesuai dengan kondisi dilapangan serta kemampuan teknis teknologi dan keuangan ukm sasaran. Proses belajar bersama dilakukan melalui pertemuan 5 kali yang dapat dilakukan di sanggar pkkdengan materi disesuaikan dengan tahapan kegiatan. Materi pelaksanaan kegiatan disajikan pada Tabel 1 diatas.

\section{HASIL DAN PEMBAHASAN}

Teknologi proses pengolahan pembuatan jamu, meskipun sederhana haruslah tetap mengacu pada proses pengolahan yang baik dan benar. Hal ini harus dilakukan demi terciptanya produk jamu dengan kualitas yang terstandar. Pada level industri kelas kecil dan menengah penanganan produk pangan khusus menggunakan bahan yang mengandung senyawa bioaktif yang tinggi. Tentu saja hal ini memerlukan investasi yang cukup besar.

Minuman kunyit asam dapat berfungsi sebagai minuman fungsional. Kunyit merupakan rempah-rempah yang dapat dijadikan sebagai bahan dasar pembuatan minuman kesehatan atau minuman fungsional. Menurut Olivia et al. (2006), rimpang kunyit (Curcuma domestica Val.) bermanfaat sebagai analgesik, anti inflamasi, antioksidan, antimikroba, pencegah kanker, anti tumor, menurunkan kadar lemak darah dan kolesterol, serta sebagai pembersih darah. Sifat senyawa bioaktif kunyit yang dapat berfungsi sebagai antioksidan dan antimikroba biasanya sangat terpengaruh oleh kondisi lingkungan seperti $\mathrm{pH}$, suhu dan oksigen. Hal ini berakibat produk yang mengandung senyawa bioaktif biasanya memiliki masa simpan yang rendah. Di sisi lain sebagai produk komersial produk dengan masa simpan yang penjang diperlukan untuk memperluas pangsa pasar yang akhirnya diharapkan dapat meningkatkan pendapatan pelaku usaha.

Identifikasi lapangan menunjukan skala mitra usaha jamu tradisional AloNa adalah skala rumah tangga. Usaha ini masih menggunakan teknologi, peralatan yang sederhana dan tidak berbasis pada proses pengolahan yang baik. Sehingga mutu produk yang dihasilkan belum terstandar dan memiliki umur simpan yang pendek. Sebagai poduk pangan, keamanan produk hingga saat siap dikonsumsi harus mendapat perhatian yang khusus.

Pengolahan kunyit menjadi jamu melalu proses sortasi, pencucian, pemarutan, perebusan, penyaringan dan pengemasan. Dari spesifikasi produk yang dihasilkan rata-rata umur simpan produk hanya 2 hari pada suhu ruang dan 4 hari pada suhu refrigerator. Terdapat rasa getir/langu pada produk. Sebagai alternative mengatasi masalah tersbut dirasa perlu untuk dilakukannya blanching bahan baku selama 15 menit. Hal ini dilakukan untuk menghentikan kerusakan akibat reaksi enzimatis dan melunakan jaringan sel agar kurkumin dan senyawa bioaktif dalam kunir dapat terekstrak lebih banyak.

Sterilisasi produk akhir juga perlu dilakukan agar produk akhir terhindar dari mikroorganisme kontaminan yang ikut masuk pada saat filling. Sterilisasi sederhana dilakukan dengan cara merebus produk jamu dalam kemasan didalam air mendidih selama 5 menit. Waktu 5 menit dirasa cukup untuk mematikan mikroorganisme kontaminan juga tetap menjaga bentuk kemasan agar tetap menarik. Pada usaha ini ditemukan adanya kendala penyimpanan. Jamu yang sudah jadi hanya disimpan di ruang terbuka sehingga masa simpan jamu tidak panjang. Oleh karena itu, ditransfer teknologi berupa alat penyimpan yang bisa juga berfungsi sebagai etalase produk yaitu show case lemari pendingin untuk produk yang dihasilkan.

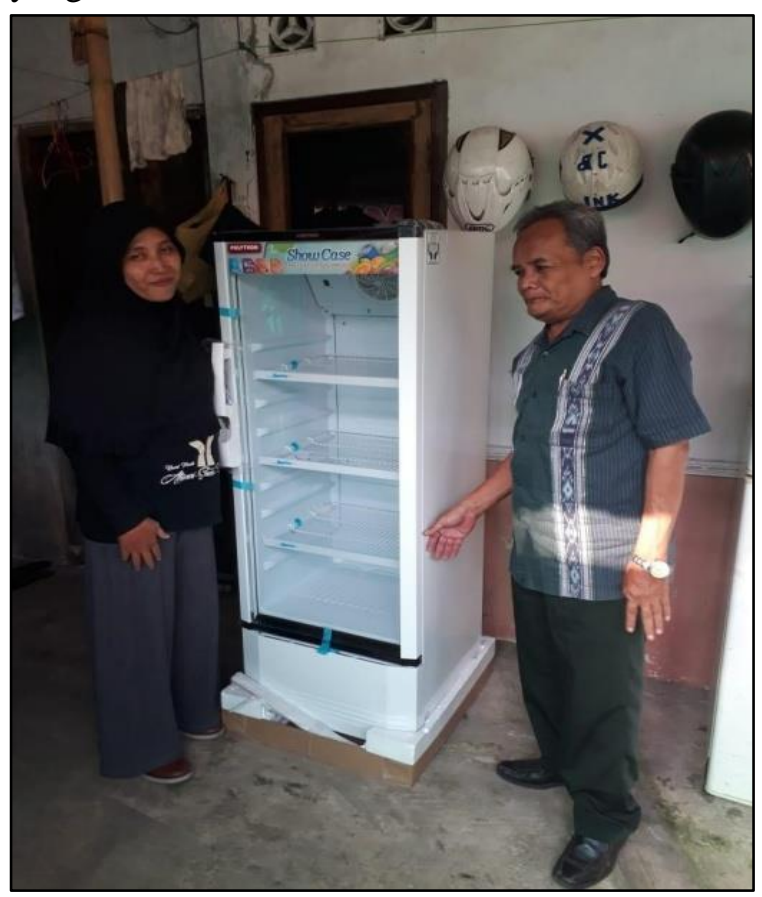

Gambar 1. Transfer Teknologi Alat Penyimpanan Produk Jamu (Show case)

Produk jamu yang dihasilkan hanya dikemas dalam botol ukuran $600 \mathrm{ml}$ yang kurang efisien dalam mengkonsumsi jamu tersebut. Permasalahan tersebut ditanggulangi dengan variasi kemasan produk berupa kemasan cup ukuran $200 \mathrm{ml}$ yang mudah dibawa dan untuk 
sekali minum. Transfer teknologi berupa alat cup sealer dan gelas berbagai macam ukuran sehingga bisa menyesuaikan permintaan konsumen. Selama ini jamu yang dipasarkan tidak memiliki label sehinga konsumen tidak mengenal nama produk ALONA. Permasalahan tersebut diatasi dengan pembuatan label merk pada kemasan jamu. Label pada kemasan tersebut diharapkan mampu mengenalkan produk jamu ALONA pada konsumen.

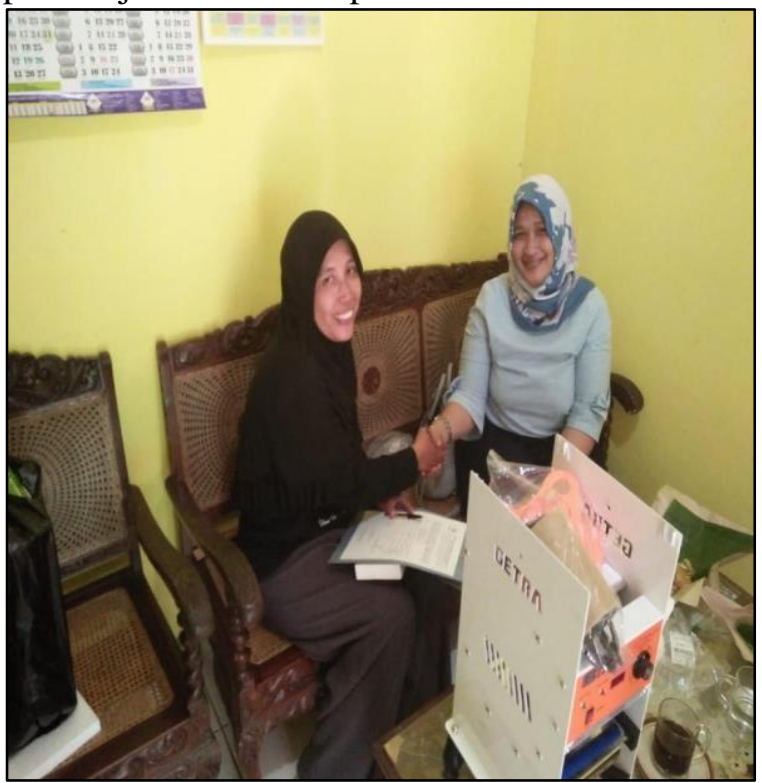

Gambar 2. Pemberian Bantuan Alat Cup Sealer

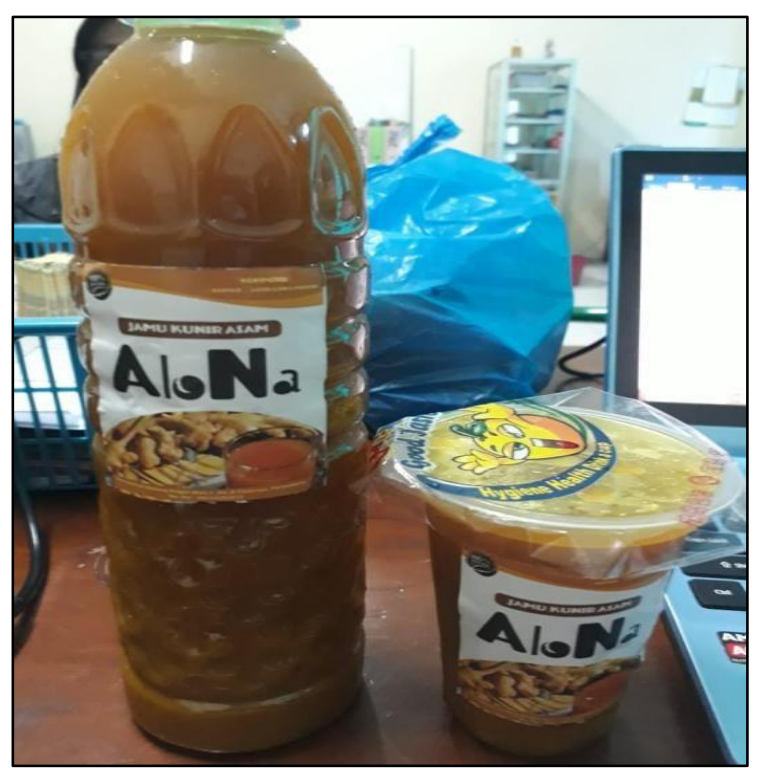

Gambar 3. Label Kemasan Jamu ALONA

Untuk mengetahui tingkat keberhasilan program pengabdian masyarakat ini, pada awal dan akhir kegiatan dilakukan pre-test dan posttest untuk mengetahui respon dan perubahan sikap dari pesera kegiatan. Hasilnya disajikan pada grafik berikut ini :

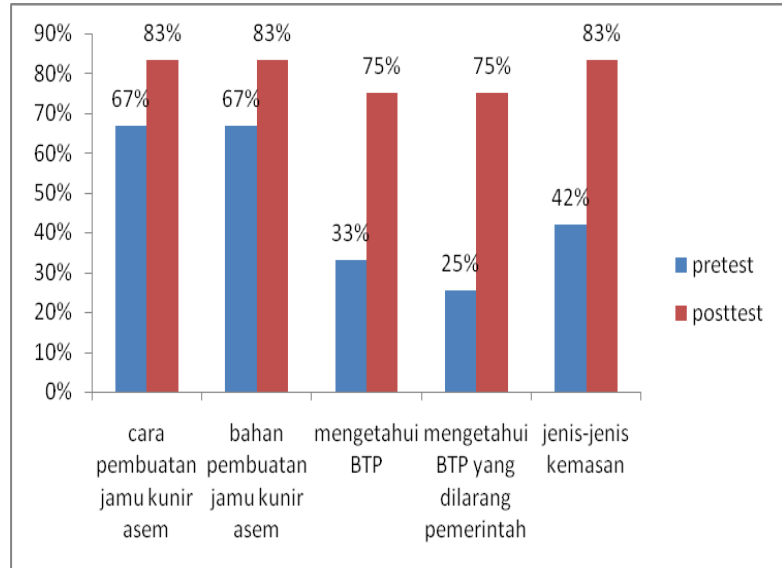

Gambar 4. Hasil Pre-test dan Post-tes Peserta

Kegiatan Pengabdian Masyarakat

Dari Gambar 4, dapat dilihat bahwa mayoritas responden awalnya tidak mengetahui arti kemasan food grade dan bahan tambahan makanan yang dilarang. Padahal kemasan yang diperuntukan untuk produk pangan memiliki persyaratan tersendiri, yaitu tidak memungkinkan terjadi transfer material baik dari produk ke kemasan dan sebaliknya (Olivia et.al, 2006). Sifat terpenting dari pengemas meliputi permeabilitas gas dan uap air serta luas permukaan kemasan. Kemasan dengan daya hambat gas yang baik dan luas permukaan yang lebih kecil menyebabkan masa simpan produk lebih lama (Liljebeg et al., 1999). Pendampingan yang dilakukan selama 3 bulan setelah semua transfer alat dan teknologi dilakukan menunjukan peningkatan omset jamu sebesar $20 \%$. Hal ini dikarenakan pelaku usaha mampu memperluas pangsa pasar sehingga omset tiap bulannya meningkat.

\section{KESIMPULAN}

Kesimpulan dari kegiatan ini adalah:

1. Kegiatan pengabdian masyarakat dilaksanakan dalam rangka meningkatkan kualitas produk jamu tradisional Alona Kecamatan Patikraja, terutama dari aspek keamanan dan pengemasan produk.

2. Rekomendasi yang dapat diberikan untuk peningkatan kualitas produk jamu tradisional Alona adalah blanching 15 menit, sterilisasi produk akhir selama 5 menit, jenis kemasan dan penyimpanan pada suhu 40C dapat memperpanjang masa simpan produk dari 4 hari menjadi 7 hari.

3. Kegiatan tersebut mendapatkan respon yang cukup positif dari masyarakat dan mitra usaha sehinga perlu diberikan tindak lanjut. 


\section{DAFTAR PUSTAKA}

Chan, E. W. C.; Y. Y. Lim; L. F. Wong; F. S. Lianto; Sk. Wong; K. K. Lim; C. E. Joe and Y. T. Lim. 2008. Antioxidant and tyrosinase inhibition properties of leaves and rhizhomes of ginger species. J Food Chem. 109:477-483.

Gunasoraya. 2011. Penentuan Umur Simpan Produk Terkemas. (Online). http:// gunasoraya.blogspot.com/2011/01/alpukat -persea-americana.html. Diakses pada tanggal 20 Maret 2016.

Hwang, Ing-San, Dr. dan Jyh-Huei Kuo. 2006. Effects of Job Satisfaction and Perceived Alternative Employment Opportunities on Turnover Intention - An Examination of Public Sector Organizations. The Journal of American Academy of Business. Cambridge. Vol. 8.

Kristianingrum. 2009. Analisis Nutrisi dalam Gula Semut. Makalah PPM. Universitas Negeri Yogyakarta. Yogyakarta.

Lestari, A. J. 2015. Kajian Sifat Fisikokimia dan Sensori Minuman Fungsional Beras Kencur Instan dengan Variasi Jenis Gula dan Penambahan Berbagai Jenis Rempah-rempah. Skripsi. UNSOED. Purwokerto.

Liljeberg, H. G. M.; A. K. E. Aerberg; and I. M. E. Bjork. 1999. Effect of the gly-cemic index and content of indigestible carbohydrates of cereal-based breakfast meals on glucose tolerance at lunch in heathy subjects. Am J Clin Nutr. 69 (4): 647-655.

Mustaufik \& H. Dwiyanti. 2007. Rekayasa pembuatan gula kelapa kristal yang diperkaya dengan vitamin $A$ dan uji preferensinya kepada konsumen. Laporan Penelitian. Peneliti Muda Dikti Jakarta. Jurusan Teknologi Pertanian Unsoed. Purwokerto (tidak dipublikasikan).

Natarajan, C. P. dan Y. S. Lewis. 1980. Technology of ginger and tumeric dalam Nari M. K., T. Prenkumar, P. N. Ravindran dan Y. R. Sarma. Proceeding of the National Seminar on Ginger and Tumeric. Calcuta Central Plantation Crops Research Inst. Kerala. India.

Paudi, F. 2012. Kandungan Nutrisi Gula Merah Kelapa. (Online). http://www.ryan-isra.net.Diakses pada tanggal 29 Juli 2016.

Permana. 2008. Bagaimana Cara Membuat Minuman Serbuk Instan. (Online) http://awpermana.dagdigdug.com/2008/05 /19/bagaimana - cara - membuat-bubukminuman-instan.Diakses pada tanggal 20 Desember 2015.

Olivia, F., S. Alam, dan I. Hadibroto. 2006. Seluk Beluk Food Supplement. Gramedia Pustaka Utama. Jakarta. 